\title{
A Pilot Study of Participatory and Rapid Implementation Approaches to Increase Depression Screening in Primary Care
}

\author{
Briana S. Last ( $\square$ brishiri@sas.upenn.edu ) \\ University of Pennsylvania
}

\section{Alison M. Buttenheim}

University of Pennsylvania School of Nursing

\section{Anne C. Futterer}

University of Pennsylvania Perelman School of Medicine

\section{Cecilia Livesey}

University of Pennsylvania Perelman School of Medicine

Jeffrey Jaeger

University of Pennsylvania Perelman School of Medicine

\section{Rebecca E. Stewart}

University of Pennsylvania Perelman School of Medicine

\section{Megan Reilly}

University of Pennsylvania Perelman School of Medicine

\section{Matthew J. Press}

University of Pennsylvania Perelman School of Medicine

\section{Maryanne Peifer}

University of Pennsylvania Perelman School of Medicine

\section{Courtney Benjamin Wolk}

University of Pennsylvania Perelman School of Medicine

\section{Rinad S. Beidas}

University of Pennsylvania Perelman School of Medicine

\section{Research Article}

Keywords: depression screening, primary care, participatory research, rapid implementation, implementation strategy design

Posted Date: June 28th, 2021

DOI: https://doi.org/10.21203/rs.3.rs-622730/v1

License: (c) (i) This work is licensed under a Creative Commons Attribution 4.0 International License. Read Full License

Version of Record: A version of this preprint was published at BMC Family Practice on November 16th, 2021. See the published version at https://doi.org/10.1186/s12875-021-01550-5. 


\section{Abstract}

Background: Most individuals with depression go unidentified and untreated. In 2016 the US Preventive Services Task Force released guidelines recommending universal screening in primary care to identify patients with depression and to link them to treatment. Feasible, acceptable, and effective strategies to implement these guidelines are needed.

Methods: This three-phased study employed rapid participatory methods to design and test strategies to increase depression screening at Penn Medicine, a large health system with 90 primary care practices. First, researchers solicited ideas and barriers from stakeholders to increase screening using an innovation tournament-a crowdsourcing method that invites stakeholders to submit ideas to address a workplace challenge. Second, a panel of stakeholders and scientists deliberated over and ranked the tournament ideas. An instant runoff election was held to select the winning idea. Third, the research team piloted the winning idea in a primary care practice using rapid prototyping, an approach that quickly refines and iterates strategy designs.

Results: The innovation tournament yielded 31 ideas and 32 barriers from diverse stakeholders (12 primary care physicians, 10 medical assistants, 4 nurse practitioners, 2 practice managers, and 4 patient support assistants). A panel of 6 stakeholders and scientists deliberated on the ideas and voted for patient self-report (i.e., through tablet computers, text message, or an online patient portal) as the winning idea. The research team rapid prototyped tablets in one primary care practice with one physician over 5 five-hour shifts to examine the feasibility, acceptability, and effectiveness of the strategy. Most patients, the physician, and medical assistants found the tablets acceptable and feasible. However, patient support assistants struggled to incorporate them in their workflow and expressed concerns about scaling up the process. Depression screening rates were higher using tablets compared to usual care; follow-up was comparable between tablets and usual care.

Conclusions: Rapid participatory methods engaged and amplified the voices of diverse stakeholders in primary care. These methods helped design an acceptable and feasible implementation strategy that showed promise for increasing depression screening in a primary care setting. The next step is to evaluate the strategy in a randomized controlled trial across primary care practices.

\section{Background}

Depression is a leading cause of disability, affecting between $8-17 \%$ of the population (1-6). Untreated depression is associated with significant medical comorbidity, functional impairment, low medication adherence, and increased risk of mortality $(2,7,8)$. Though a variety of mental health interventions reduce symptoms and other sequelae, only a fraction of people with depression receive treatment (9-12). One major challenge is the identification of individuals with depression (13, $14)$; as many as half of cases of depression go undiagnosed $(15,16)$.

Primary care is an optimal place to identify individuals with depression. First, due to the association between psychiatric disorders and physical diseases, primary care practices serve individuals with elevated rates of depression compared to the general population (17-21). Second, patients overwhelmingly trust their primary care clinicians and may be more willing to seek treatment with their encouragement $(22,23)$. Screening and subsequently treating patients for depression in primary care settings is effective at increasing response to treatment and remission, controlling physical disease, and reducing total healthcare costs (24-27).

In response to this mounting evidence, national organizations, payers, policymakers, and health systems have begun to transform their depression screening practices. The US Preventive Services Task Force now recommends that health systems implement universal depression screening protocols $(28,29)$. These recommendations prompted the Centers for Medicare \& Medicaid Services (CMS) to cover annual depression screening for Medicare beneficiaries in primary care and to financially incentivize health system universal screening practices (30). The National Committee for Quality Assurance, the national accrediting body that approves quality of care performance metrics, approved the Patient Health Questionnaires (PHQ) as potential depression screeners. These include the PHQ-2, a well-validated 2-item tool shown to be sensitive and specific to 
Major Depressive Disorder, and the PHQ-9, the 9-item version of the questionnaire (31). The PHQ-2 and PHQ-9 have become the depression assessments of choice for many health systems.

Despite payer incentives, there have been few specific guidelines to support health system implementation of universal depression screening in primary care. Many health systems have attempted to increase depression screening and have encountered several barriers (32). Just before the 2016 universal screening guidelines were implemented, nationally representative studies found that depression screening occurred at rates of just $3-4 \%$ in primary care practices $(33,34)$. Thus, acceptable and feasible implementation strategies to increase depression screening in primary care are needed.

In our study, we used participatory and rapid implementation methods that involved stakeholders across primary care at the University of Pennsylvania Health System (Penn Medicine) to design and pilot strategies to increase depression screening and follow-up. Stakeholder participation ensures the acceptability and feasibility of implementation efforts (35). Large-scale health system initiatives to increase universal depression screening must incorporate the interests of all stakeholders involved in the process: leaders from Primary Care and Psychiatry, clinicians, staff, and patients. In addition to growing recognition that stakeholder input is crucial to implementation success, it is now acknowledged that the gap between research and practice is sometimes prolonged by traditional randomized controlled trial implementation studies, that, though rigorous, are resource intensive. Rapid implementation methods are an increasingly popular approach to design strategies (36-38). Rapid implementation allows researchers to "fail fast" and quickly refine their strategies before they scale up their approach. Our study provides health systems with a specific strategy to improve mental health assessment in primary care settings, as well as a general framework and set of methods to design implementation strategies for quality improvement projects.

\section{General Methods}

\section{Context}

Penn Medicine's Department of Psychiatry and Primary Care Service Line initiated a staged and adapted implementation of the evidence-based Collaborative Care Model-referred to as the Penn Integrated Care program (PIC; 39)-an approach for managing psychiatric disorders in primary care that combines mental and physical health services into a single setting $(40,41)$. Healthcare professionals from multiple disciplines work together to coordinate and treat patients. The Collaborative Care Model improves access to care and has shown promise in improving clinical outcomes for psychiatric and physical health conditions $(42,43)$.

In 2018, Penn Medicine launched the PIC program in eight of its 90 primary care practices. These eight practices in Philadelphia serve over 90,000 patients and range in size from 4 to 26 primary care clinicians. The PIC program is modeled on the traditional Collaborative Care Model, though it also includes a "Resource Center" to assess and triage Penn Medicine primary care patients in need of any mental health services. All three phases of our study were conducted in PIC practices. This decision was based on consistent feedback from stakeholders in primary care that mental health screening can only be ethically conducted if follow-up care is readily available.

\section{Overview of Participants and Procedures}

Our study includes three distinct phases. In Phase 1, we conducted an innovation tournament to generate strategies to improve depression screening. Innovation tournaments are a novel participatory method in which stakeholders are invited to submit their ideas to address a specific challenge faced by a workplace, industry, or service system $(44,45)$. We targeted leaders from Primary Care and Psychiatry, clinicians, and staff involved in depression screening (i.e., who interface with the PHQ-2 and PHQ-9) as our key stakeholders. We analyzed responses from the innovation tournament using a content coding approach to organize the ideas into themes. In Phase 2, we held a panel with expert stakeholders and scientists to discuss the ideas. After extended deliberation, the panel voted on a winning idea from the tournament. In Phase 3, we piloted the winning idea in a PIC practice with one physician over 5 five-hour shifts. When piloting, we used a mixed methods rapid implementation approach called rapid prototyping, which systematically tested and refined the strategy to ensure the implementation method 
was acceptable and feasible. All study procedures were approved by the University of Pennsylvania's Institutional Review Board.

\section{Phase 1 - The Innovation Tournament}

\section{Methods}

Procedure. In order to generate acceptable and feasible methods to increase depression screening in primary care, we deployed an innovation tournament. Innovation tournaments have been shown to be effective in Penn Medicine and community settings for designing implementation strategies that empower stakeholders and increase investment in the suggested ideas $(45,46)$. The innovation tournament was based on methods developed by the Penn Medicine Center for Healthcare Innovation and prior work with clinicians (45-47).

Tournament platform. The Penn Medicine Center for Healthcare Innovation hosts a web-based platform called "Your Big Idea" to run tournaments. Researchers post prompts about a healthcare challenge to crowdsource solutions. Participants can respond to these prompts, called "Idea Challenges," with an idea, rate other participants' ideas on a Likert-type 1-5 "star" scale, and comment on other participants' ideas.

Tournament prompts. The "Idea Challenges" were designed through a participatory process. The research team developed several different prompts that asked participants how they would improve depression screening. After consultation with leaders in the Penn Medicine Center for Healthcare Innovation with experience conducting innovation tournaments, Idea Challenges were narrowed down to three options and a question was added about barriers to depression screening. The research team attended staff meetings (attended by practice leaders, clinicians, staff, and administrators) at two of the PIC practices and asked attendees to respond to each of the three Idea Challenges. Meeting attendees discussed the advantages and disadvantages of each prompt. At both meetings, the consensus was to focus the question on increasing screening rates. The final prompt was: "What's your big idea for increasing depression screening rates in the primary care setting?" The barrier question was "What currently gets in the way of screening patients for depression in your clinic?"

Recruitment. First, we invited all stakeholders (leaders from Primary Care and Psychiatry, clinicians, and staff) in PIC practices by e-mail to participate in the innovation tournament called "Increasing Depression Screening Rates in Primary Care." Three emails in total were sent to a total of 420 participants. In terms of the tournament response, 150 stakeholders (36\%) opened the first email and 17 (4\%) clicked on the "Your Big Idea" link; 122 (29\%) opened the second email and 15 (4\%) clicked the link; $118(28 \%)$ opened the third email and 14 (3\%) clicked the link. To enhance participation, we posted flyers (see Figure 1) advertising the innovation tournament at seven of the eight PIC primary care clinics; one program did not respond to the request. The team also spent time in staff rooms in three of the clinics to recruit clinicians and staff. The landing page for the innovation tournament, which was live between March 12 and April 5, 2019, is available for viewing at https://bigidea.pennmedicine.org/depression.

\section{Results}

Ideas coding. When the innovation tournament closed, 31 ideas and 32 barriers were submitted through the Your Big Idea platform from 12 primary care physicians, 10 medical assistants (MA), 4 nurse practitioners, 2 practice managers, and 4 Patient Support Assistants (PSAs). The 31 ideas received 48 ratings; eight ideas received 5 stars (out of a 5-star system) and these top-rated ideas all proposed that patients complete the PHQ-2/9 via self-report either on tablet computers in the waiting area, by text message before their appointments, or through MyPennMedicine (Penn Medicine's confidential online patient portal) before their appointments.

The research team organized a meeting with a panel of expert stakeholders and scientists to deliberate and vote on the innovation tournament winning idea. To reduce the burden on the panel, the research team refined the list of 31 ideas into themes using a content coding approach (48). The team coded the 31 ideas together and when there were disagreements, they resolved them by consensus. The ideas were organized into four themes: (1) patient self-report (e.g., patients complete the 
screener on tablet computers in the waiting room, through MyPennMedicine communications, or by text message; $n=12) ;(2)$ reframing (e.g., changing the wording of the screener, changing the way it is introduced; $n=8$ ); (3) workflow changes (e.g., putting screening results in the "Vitals" or "Chief Complaint" sections of the electronic health record Epic $\odot$, create reminders in Epic (C; $n=7$ ); (4) patient education (e.g., an anti-stigma campaign, clinician-provided psychoeducation about depression, flyers providing education regarding signs and symptoms placed strategically in clinics; $n=4$ ). See Table 1 for the ideas, their respective themes, and the barriers identified by stakeholders.

\section{Phase 2 - The Panel of Expert Stakeholders \& Scientists}

\section{Methods}

Participants. We invited a panel of expert stakeholders and scientists to discuss the ideas from the innovation tournament and to decide on the winning idea. To ensure that the panel was representative of all stakeholders involved in depression screening as part of the PIC program (from PSAs who check patients in at the front desk, to primary care clinicians, to patients, to social workers receiving referrals, etc.) we invited stakeholders from each group. To recruit MAs and PSAs, we asked the eight PIC practice managers to invite their staff to our upcoming meeting. To ensure patient participation, a primary care leader invited a patient from Penn Medicine's primary care patient advisory board who had participated in the PIC program. In addition, two members of the research team-one expert in implementation science involved in the PIC program (CBW) and one expert in applying behavioral science methods to health systems (AMB) -were invited to participate. In total, the panel included six voting members: one social worker providing mental health services in the PIC program, one primary care physician in the PIC program, one leader in psychiatry, one patient from a PIC practice participating in the PIC program, and the two scientists on our research team.

Procedure. The one-hour meeting took place over lunch. BSL summarized the innovation tournament results in the first fiveminutes and guided the panel discussion with the following questions: "Which ideas are most surprising?"; "Are there any ideas you feel are missing from the list that would be important to test?"; "Which ideas can we immediately rule out?"; and "Which ideas seem most feasible, acceptable to clinicians and patients, and immediately actionable?"; and "Which ideas are your favorites?"

The panel discussed for 50 minutes and then anonymously rank-choice voted on their preferred idea theme (i.e., patient selfreport, reframing, workflow changes, or patient education) using paper ballots. The discussion was transcribed verbatim.

The patient participating in the panel was compensated \$100. Five innovation tournament participants with the most elaborated strategy to implement the winning idea were sent $\$ 100$, and an additional five randomly selected innovation tournament participants were sent $\$ 100$ to reward their participation.

Analysis Plan. The discussion transcript was analyzed using content analysis to identify themes (48). Two members of the research team (BSL and ACF) identified themes and repeating ideas. Disagreements were resolved by discussion and consensus. Rank-choice votes were analyzed using an instant runoff election method-a vote counting method for rank-choice elections - to select the winner of the innovation tournament (49). The software used to analyze the election results was OpaVote@.

\section{Results}

Discussion Themes. Table 2 displays the themes, sub-themes, and ideas from the panel discussion. BSL and ACF identified several repeating ideas from the panel discussion. The discussion was divided into two parts: a discussion of the barriers to depression screening and a discussion of the ideas submitted to the innovation tournament.

In terms of the barriers to screening, panelists were concerned about MAs administering the depression screener. The majority of panelists (67\%) stated that MAs are not clinically trained to administer a sensitive mental health questionnaire. Most (67\%) panelists voiced that the PHQ-2/9 were designed and validated for self-administration. Panelists (67\%) also suggested that

Page 5/31 
both clinicians, MAs, and patients may not fully understand the rationale for administering the depression screener. Finally, panelists (33\%) indicated that there are several technological challenges related to the way depression screening results are integrated in Epic@.

Panelists discussed the ideas submitted to the innovation tournament. Most panelists (67\%) focused on the fact that the "reframing" idea revealed that those submitting ideas to the innovation tournament were less focused on increasing screening rates, but rather improving the accuracy of screens. That is, tournament "reframing" ideas described ways to facilitate a deeper connection between providers and patients; they also recommended changing the wording of the PHQ-2/9 questions for the sake of clarity. The majority of panelists (83\%) liked the idea of patient self-report of the depression screener, particularly the implementation of tablet computers in the patient waiting area. Panelists discussed safety and liability concerns with precheck-in text messages through MyPennMedicine such as the need to ensure that the endorsement of suicidality could be quickly identified and acted upon if the patient is completing the PHQ-9 outside of the office. Most panelists (83\%) also liked the idea of patient education and thought it was necessary, though one panelist voiced that patient education would unlikely increase rates; rather it would improve the accuracy of the depression assessment. Panelists felt that both ideas would also be feasible and acceptable to implement in the practices.

Election Results. The instant runoff election winner to the rank-choice election was the patient self-report idea. The panel determined that the ideas that suggested patients complete the depression screener confidentially either on tablet computers, through MyPennMedicine ahead of the visit, or via text message were the most viable and potentially impactful strategies to improve depression screening.

\section{Phase 3 - Piloting the Winning Innovation Tournament Strategy}

\section{Overview of Rapid Prototyping}

Rapid prototyping is the systematic testing of ideas in order to create and refine strategies quickly (50). First employed in industrial design, this method has been extended to healthcare contexts where effective implementation strategies don't yet exist and immediate feedback is necessary to optimize healthcare quality and safety (38,51-55). Rapid prototyping facilitates learning as quickly as possible whether a strategy works and allows researchers to make adjustments as needed. Identified problems are documented and the implementation plan is revised. A subsequent experiment is conducted to see if it resolves the problem and to identify any further problems. Rapid prototyping is done iteratively and cyclically, much like Plan-Do-StudyAct cycles frequently used in quality improvement studies (56). See the analysis plan below for the process description.

\section{Method}

Participants. To evaluate the feasibility and acceptability of the winning innovation tournament idea, we planned to first pilot in two PIC primary care practices before scaling the project up. The research team met with leadership in the Primary Care Service Line, including leaders from each PIC practice, and two practices agreed to participate in the pilot. Along with an informational technological consultant from the health system, two members of the research team met with the practice manager and the lead clinician of each practice to discuss the pilot workflow changes. Given that piloting the strategy would involve substantial changes to the workflow, one practice requested to initially pilot the tablets with one physician who already adhered to depression screening guidelines before scaling to the entire practice. Due to COVID-19 pandemic related physical distancing precautions, the pilot was halted after prototyping in one practice with one physician.

\section{Procedure}

Study Design. Data collection was conducted according to a withdrawal design method-i.e., a method in which the intervention is "withdrawn" systematically to allow for a comparison between changes in the outcome in baseline versus intervention periods (57). The research team was present on specific "intervention" days to use tablets for depression screening, and on alternating "baseline" days, depression screening was conducted as it was normally conducted in the practice. 
In the case of this particular PIC practice, usual care for depression screening involves the MAs administering the PHQ-2 to patients verbally. MAs enter patients' responses in Epic@. If the patient screens positive on the PHQ-2 (a score of $>2)$ MAs provide a paper version of the PHQ-9 for the patient to complete; the patient is then expected to hand off the completed questionnaire to their clinician. Once the clinician arrives in the examination office, the clinician is expected to manually enter the depression screening data in Epicœ.

Materials. Two tablet computers were purchased to conduct the rapid prototyping. To ensure patient safety and confidentiality, the health system encrypted each tablet and installed Epic Welcome@ , the patient-facing application version of Epic@ . Patients complete questionnaires and consent forms on Epic Welcome $\odot$ and their responses sync in real-time with the clinician-facing version of Epic@. On Epic Welcome@, when patients complete the PHQ-2, the questionnaire automatically expands into the PHQ-9 if patients' score on the PHQ-2 is greater than or equal to 1 (endorsing at least some symptoms on either of the two items). Notably, this is a more liberal cut-off than CMS and health system guidelines, which recommend follow-up at a PHQ-2 score greater than 2. This discrepancy provides further evidence that significant technological barriers prevent health system standardization of depression screening, as described by innovation tournament participants and panelists.

\section{Rapid Prototyping Analysis Plan}

Rapid prototyping was conducted over five days (i.e., five 5-hour shifts) in a PIC practice. The three steps of the rapid prototyping process are outlined below.

Step 1 - Design. Before each 5-hour shift, members of the research team (BSL and ACF) designed a plan to use tablet computers to screen for depression. This plan included decisions about the workflow, materials needed, the staff involved in the process, and the location of screening. To ensure rapid feedback, the research team collected field notes and interviewed stakeholders (PSAs, the practice manager, MAs, the physician, and patients) involved in the pilot. Field note templates and qualitative interview guides are provided in Additional File 1 and Additional File 2 respectively. Qualitative interviews were transcribed verbatim in real-time. The research team also documented whether the PHQ-2 was administered.

Step 2- Evaluate and Review. Immediately after a 5-hour shift of rapid prototyping, the research team met to review the findings. Field notes and interviews were read aloud together and synthesized to eliminate redundancies and ascertain discrepancies. Qualitative data were analyzed using a rapid immersion/crystallization approach (36,58-60). BSL and ACF, who had been extensively immersed in the experience, developed impressionistic summaries of what they learned.

Researchers' holistic impressions of the experience were crystallized through discussion and written documentation. To ensure systematicity, the research team also recorded key features of each rapid prototyping cycle: (1) a summary of the workflow design; (2) workflow successes; (3) workflow challenges; and (4) a summary of the changes to be tested in the next cycle.

Step 3 - Refine and Iterate. After determining the necessary workflow changes, the research team planned to refine the tablet screening process. This process sometimes involved writing scripts for the PSAs presenting tablets to patients to ensure that patients received uniform rationale about the PHQ-2. Other times, this involved placing laminated sheets with screenshots to guide MAs and the clinician to find the PHQ-2 depression screening data in their version of the electronic health record. The research team communicated with the practice ahead of the shift to ensure the changes were acceptable. The new iteration was then tested in the subsequent shift. In order to be able to directly evaluate whether the specific iteration of the strategy was superior to the previous cycle's, attributes were not modified if they did not present challenges. This process repeated for each cycle.

\section{Outcomes}

Qualitative Data. Field notes and interview transcripts from each cycle of the rapid prototyping process were collected and analyzed to iteratively improve the pilot process. 
Quantitative Data. The primary outcomes for the pilot were PHQ-2 and PHQ-9 screening rates and PHQ-2 follow-up. According to CMS in 2019, follow-up to the PHQ-2 (if the score is greater than 2) is considered complete if one of the following actions is taken: (1) the patient completes a more extended depression questionnaire (i.e., PHQ-9) or suicide assessment; or (2) the primary care clinician refers the patient to a mental health clinician; or (3) the clinician prescribes depression medications; or (4) the clinician documents a depression follow-up plan; or (5) the clinician documents a depression diagnosis.

Depression screening data were extracted from Epic@ . Patient eligibility for the screener, PHQ-2 scores, PHQ-9 scores, medication list, medical diagnoses, referrals, and patient notes were extracted from Epic@ for intervention and baseline shifts. To ensure a fair comparison and avoid any potential confounds related to the timing of the visit, baseline shift data were collected from the same time window and same physician as the intervention shifts. Because tablets automatically triggered the PHQ-9 at a lower score (a PHQ-2 score > 1) than CMS requirements and the usual care practice (a PHQ-2 score >2), PHQ-9 and follow-up rates were compared statistically based on CMS requirements (PHQ-2 score > 2).

\section{Results}

Qualitative Results. Table 3 displays the rapid prototyping process results from each day of piloting; Additional File 3 narratively describes these detailed results. Figure 2 displays the modifications of each rapid prototyping cycle and tablet administration results.

Broadly, rapid prototyping revealed that tablet computers were acceptable and feasible to most stakeholders (the physician, the practice manager, MAs, and patients) involved in depression screening. However, PSAs found the additional responsibilities of checking patients in, handing off the tablets, and introducing the screener to patients to be somewhat disruptive to their workflow. In addition, anywhere between 1-3 patients during the first four five-hour shifts did not complete the questionnaire via tablet either due to the patient's physical limitations, because the workflow was not yet mastered by stakeholders, or because there was not sufficient time to complete the depression screener via tablet. These patients completed the PHQ-2 verbally with the MA (i.e., through usual care). After several refinements were made during the rapid prototyping process, the process of depression screening via tablet improved and the PSAs eventually described that the workflow adjustments were "smooth sailing." During the final shift, all patients were screened via tablet and stakeholders considered the pilot a "success." Stakeholders made several recommendations for how to scale up the process across PennMedicine primary care practices, including transformations to Epic@ and standardization of depression screening workflows across the health system.

Quantitative Results. Overall, the rapid prototyping process resulted in comparable PHQ-2 screening rates to usual care (given that the practice participating in the pilot already screened all eligible patients). However, tablets significantly increased PHQ-9 screening rates. Follow-up between usual care and piloting days were comparable. $Z$ test results for non-significant findings should be viewed in light of the fact that the pilot study was not adequately powered to detect a statistical difference.

On baseline days 30 out of 30 (100\%) eligible patients were administered the PHQ-2. On intervention days 35 out of 36 (97\%) of eligible patients were administered the PHQ-2. According to field notes, the patient whose PHQ-2 data were not recorded was given a tablet, indicating that responses were not synced with Epic@. Given that the practice participating in the pilot was highly compliant with PHQ-2 screening guidelines, differences between baseline and intervention days were not significant $(z=$ $0.92, p=0.36)$.

For those patients whose PHQ-2 score was positive (a score >2), PHQ-9 screening was evaluated. On baseline days, 1 out of 3 (33\%) of eligible patients were administered the PHQ-9. On intervention days, 6 out of $6(100 \%)$ of eligible patients were administered the PHQ-9. Differences between baseline and intervention days were significant $(z=-2.27, p=0.02)$.

Using the more inclusive definition of PHQ-2 follow-up per CMS guidelines (described above), follow-up rates were extracted from Epic@. On baseline days, 2 out of 3 patients (67\%) received follow-up after a positive PHQ-2 screen. On intervention days, 6 out of 6 patients (100\%) received follow-up after a positive PHQ-2 screen. Differences between baseline and intervention days were not significant $(z=-1.50, p=0.13)$. 


\section{Discussion}

\section{Major Findings}

Our pilot study employed participatory and rapid implementation methods to increase universal depression screening in Penn Medicine primary care practices. First, we employed an innovation tournament to gather ideas from stakeholders (leaders from Primary Care and Psychiatry, clinicians, and staff) about how to increase depression screening in primary care. Second, a panel of expert stakeholders and scientists deliberated and voted on the best innovation tournament idea to pilot. The panel determined that rather than the usual care practice of verbal PHQ-2 administration by MAs, the research team should pilot an electronic self-report method. Third, we piloted this winning idea in one primary care practice with one physician over five cycles. Using an innovative rapid implementation method called rapid prototyping, we designed and refined a strategy to screen patients for depression with tablet computers. Our pilot study found that using a tablet for patient self-administration of depression questionnaires was feasible and acceptable across stakeholder groups, though PSAs expressed concern about the additional responsibilities resulting from these workflow changes. Despite significant workflow changes, in our limited sample PHQ-2 screening rates using tablets were comparable to usual care screening rates given that the practice/physician we worked with already accomplished universal (i.e., 100\%) screening rates. Moreover, PHQ-9 screening rates were significantly higher using the tablet. Follow-up rates for usual care and intervention days were comparable. PHQ-9 screening rates were likely higher because, unlike usual care at the practice that tasked MAs with following up on the PHQ-2, tablet computers automatically triggered and generated the PHQ-9 screener if a patient screened positive on the PHQ-2. Whereas usual care necessitated continuous and deliberate human intervention, the app on the tablet computer generated the PHQ-9 by default.

\section{Strengths and Weaknesses of Participatory and Rapid Implementation Approaches}

This case study revealed the advantages and disadvantages of using participatory and rapid implementation approaches to strategy design. This study is unique for its inclusion of a variety of stakeholder perspectives across the three study phases. As a consequence of health system incentives for physicians to see more patients and meet more demands, more responsibilities -formerly within the sole purview of physicians-are being shifted onto non-physician and often non-clinical workers (61). The few studies that have sought the perspectives of non-physicians have discovered that health system transformations rarely incorporate their often diverging concerns $(62,63)$.

Consistent with this work, the panel discussion of expert stakeholders and scientists revealed that different stakeholder groups have different knowledge and priorities about screening that need to be addressed by health systems (64-66). For example, the panelists felt that the reframing ideas by the diverse innovation tournament participants showcased a misunderstanding about the rationale for screening. The panelists also discussed some of the drawbacks of task-shifting through the employment of non-clinical staff and MAs for screening. The panel suggested that patients, clinicians, and staff may require additional education to understand the rationale for depression screening and that not all clinicians feel equipped to provide depression follow-up, all of which may indirectly impact screening rates (64,67-71). Field notes and qualitative interviews from the rapid prototyping phase again displayed conflicting stakeholder perspectives. Though most patients found depression screening on the tablet acceptable, a contingent could or would not use the tablets for various reasons (e.g., physical ability, digital literacy, concerns about the impersonality of the questionnaire). PSAs felt that they were being given more responsibilities that were disruptive to the workflow, whereas clinical staff found the tablet screening acceptable and feasible. Health systems must incorporate these different perspectives in future implementation efforts to ensure their success. For example, future efforts using tablets to screen for depression might consider developing a back-up plan for patients who dislike or cannot use a self-report electronic screener and consider reducing PSA burden.

Another strength of the rapid implementation approach was the ability to get feedback quickly from stakeholders who were invested in the quality improvement effort. The innovation tournament was an efficient method to reach engaged stakeholders in the PIC program and the panel meeting enabled the research team to promptly evaluate the feasibility of the innovation tournament ideas. Rapid prototyping allowed the research team to receive immediate feedback on whether the stakeholderproposed changes were acceptable, feasible, and increased screening rates. In our pilot study, several of the stakeholder- 
proposed changes were successful, and others were not (e.g., conducting the PHQ-2 in the exam room). We were able to present the data to stakeholders and rapidly change course when there was agreement that the current iteration of the strategy was ineffective. Altogether, our work suggests that there are significant advantages for researchers to employ these methods. Rapid experimentation that engages the entire workforce involved in health system transformations is the necessary next step to realize the promise of a learning health system $(51,53)$.

There were also several weaknesses to these participatory and rapid implementation methods. Most significantly, the stakeholders engaged in the process (from the innovation tournament to the rapid prototyping phase) were heavily invested in system change, concerned about increasing depression screening, and motivated to voice their input in the research process. These stakeholders were not representative. The stakeholders that chose to participate in the tournament tended to provide highly elaborate responses, which accords with the literature suggesting that the most engaged stakeholders who are eager to share their ideas will submit ideas to the tournament (44-46,72). Stakeholder self-selection was perhaps most evident in the high practice screening rates at baseline. We worked with a practice/physician for the pilot that already had high PHQ-2 screening rates so the practice felt assured they would not risk compromising patient care during the pilot. However, similar to other health systems, depression screening rates across Penn Medicine primary care practices are far more variable, ranging from $10-90 \%(67,70,73,74)$. The level of engagement and motivation in the process is not surprising given our approach, which relies on early adopters and those willing to engage in health system experimentation. Going forward, leveraging the leadership and embeddedness of these implementation champions will be crucial to effectuating large-scale change in the entire health system (75).

Beyond the limitations of the methods, our study also has several specific limitations. First, we were not able to scale up the pilot beyond one physician in one practice due to the onset of the COVID-19 pandemic, which halted research. Though our study yielded important lessons on innovative participatory and rapid methods to improve implementation design, depressing screening rates from the pilot study should be appropriately contextualized in light of the small sample. Researchers are planning to conduct further examinations in the health system to scale up this experimentation when physical distancing guidelines are no longer in place.

Another limitation of our study is that due to the preliminary nature of the investigation, permanent modifications to the electronic health record that would have affected the whole health system were not feasible. For example, through Epic@ it is possible to automate the assignment of the depression questionnaire to avoid PSA burden. Yet due to the preliminary nature of our study, the research team was not able to execute this change. During the rapid prototyping process, PSAs found assigning the PHQ-2 to be disruptive and burdensome. This particular challenge may not generalize to a large-scale implementation initiative where such changes would be permitted.

\section{Conclusions}

Employing participatory and rapid implementation methods to increase depression screening in primary care is effective at engaging stakeholders, generating investment in the project, and improving the design of implementation strategies. Our findings reveal that involving all stakeholders impacted by these implementation efforts can provide important guidance for how to effectuate large-scale change in the health system. Health systems and payers must attend to the diversity of perspectives from all stakeholders affected by transformations in healthcare provision. In particular, while electronic depression screening is considered a priority for many stakeholders, our pilot study found that a contingent of patients could not complete this method and that PSAs were saddled with additional responsibilities that they perceived to be disruptive. In order to capture accurate depression rates, screening practices must allow for implementation flexibility. More broadly, our preliminary results suggest that these methods can improve universal depression screening in primary care practices. We were able to leverage participatory and rapid approaches to design implementation strategies to improve screening at relatively low cost, with sustained stakeholder engagement and buy-in, and without disrupting workflows permanently. Health systems committed to implementing evidence-based practices beyond depression screening stand to gain from these rapid, stakeholder-centered design methods.

Page 10/31 


\section{Abbreviations}

PIC = Penn Integrated Care; MA = Medical Assistant; PSA = Patient Support Assistant; $\mathrm{PHQ}=$ Patient Health Questionnaire; CMS $=$ The Centers for Medicare \& Medicaid Services

\section{Declarations}

\section{Ethics Approval and Consent to Participate}

All procedures were reviewed and approved by the University of Pennsylvania Institutional Review Boards and are in accordance with the Declaration of Helsinki. The protocol (832617) was deemed exempt by the University of Pennsylvania Institutional Review Board for the minimal risk it posed to human subjects, and therefore the need for informed consent to participate was waived.

\section{Consent for Publication}

Not applicable.

\section{Availability of Data and Materials}

The datasets generated and analyzed during the current study are not publicly available due to the sensitive and identifiable nature of qualitative data and small pilot study data, but de-identified data are available from the corresponding author on reasonable request.

\section{Funding}

Funding for this study was provided by grants from the National Institute of Mental Health (P50 MH 113840, Beidas, Buttenheim, Mandell, MPI). BSL also receives funding support from the National Science Foundation Graduate Research Fellowship Program (DGE-1321851).

\section{Authors' Contributions}

BSL conceived of and designed the research study; acquired and analyzed the data; interpreted the data; drafted the manuscript and substantially revised it. AMB analyzed the data; interpreted the data; and substantially revised the manuscript. ACF acquired and analyzed the data; interpreted the data; and substantially revised the manuscript. CL helped design the research study; acquired and analyzed the data; and substantially revised the manuscript. JJ helped design the research study; acquired the data; and substantially revised the manuscript. RES analyzed the data and substantially revised the manuscript. MR acquired the data and substantially revised the manuscript. MP substantially revised the manuscript. CBW helped conceive of and design the research study; analyzed the data; interpreted the data; and substantially revised the manuscript. RSB helped conceive of and design the research study; interpreted the data; and substantially revised the manuscript. All authors approved the submitted version; have agreed to be accountable for the contributions; and attest to the accuracy and integrity of the work, even aspects for which the authors were not personally involved.

\section{Acknowledgments}

We are grateful for the support and partnership of the many leaders, clinicians, staff, and patients at PennMedicine who contributed to this research.

\section{Footnotes}

Not applicable.

\section{References}


1. Kessler RC, Chiu WT, Demler O, Walters EE. Prevalence, severity, and comorbidity of 12-month DSM-IV disorders in the National Comorbidity Survey Replication. Archives of general psychiatry. 2005;62(6):617-27.

2. Kessler RC. The costs of depression. Psychiatric Clinics. 2012;35(1):1-14.

3. Brody DJ, Pratt LA, Hughes JP. Prevalence of depression among adults aged 20 and over: United States, 2013-2016. 2018;

4. Weinberger AH, Gbedemah M, Martinez AM, Nash D, Galea S, Goodwin RD. Trends in depression prevalence in the USA from 2005 to 2015: widening disparities in vulnerable groups. Psychological medicine. 2018;48(8):1308.

5. Ettman CK, Abdalla SM, Cohen GH, Sampson L, Vivier PM, Galea S. Prevalence of depression symptoms in US adults before and during the COVID-19 pandemic. JAMA network open. 2020;3(9):e2019686-e2019686.

6. Lim GY, Tam WW, Lu Y, Ho CS, Zhang MW, Ho RC. Prevalence of depression in the community from 30 countries between 1994 and 2014. Scientific reports. 2018;8(1):1-10.

7. DiMatteo MR, Lepper HS, Croghan TW. Depression is a risk factor for noncompliance with medical treatment: metaanalysis of the effects of anxiety and depression on patient adherence. Archives of internal medicine. 2000;160(14):2101-7.

8. Katon WJ. Epidemiology and treatment of depression in patients with chronic medical illness. Dialogues in clinical neuroscience. 2011;13(1):7.

9. Ahrnsbrak R, Bose J, Hedden SL, Lipari RN, Park-Lee E. Key substance use and mental health indicators in the United States: Results from the 2016 National Survey on Drug Use and Health. Center for Behavioral Health Statistics and Quality, Substance Abuse and Mental Health Services Administration: Rockville, MD, USA. 2017;

10. Cuijpers P, van Straten A, Andersson G, van Oppen P. Psychotherapy for depression in adults: a meta-analysis of comparative outcome studies. Journal of consulting and clinical psychology. 2008;76(6):909.

11. Cuijpers P, Andersson G, Donker T, van Straten A. Psychological treatment of depression: results of a series of metaanalyses. Nordic journal of psychiatry. 2011;65(6):354-64.

12. Driessen E, Cuijpers P, de Maat SC, Abbass AA, de Jonghe F, Dekker JJ. The efficacy of short-term psychodynamic psychotherapy for depression: a meta-analysis. Clinical psychology review. 2010;30(1):25-36.

13. Chekroud AM, Foster D, Zheutlin AB, Gerhard DM, Roy B, Koutsouleris N, et al. Predicting barriers to treatment for depression in a US national sample: a cross-sectional, proof-of-concept study. Psychiatric services. 2018;69(8):927-34.

14. Simon GE, Fleck M, Lucas R, Bushnell DM, group L. Prevalence and predictors of depression treatment in an international primary care study. American Journal of Psychiatry. 2004;161(9):1626-34.

15. Sheehan DV. Depression: underdiagnosed, undertreated, underappreciated. Manag Care. 2004 Jun;13(6 Suppl Depression):6-8.

16. Waitzfelder B, Stewart C, Coleman KJ, Rossom R, Ahmedani BK, Beck A, et al. Treatment Initiation for New Episodes of Depression in Primary Care Settings. J Gen Intern Med. 2018/02/08 ed. 2018 Aug;33(8):1283-91.

17. Rosmond R. Obesity and depression: same disease, different names? Medical hypotheses. 2004;62(6):976-9.

18. Carney RM, Freedland KE. Depression and coronary heart disease. Nature Reviews Cardiology. 2017;14(3):145.

19. Arnow BA, Hunkeler EM, Blasey CM, Lee J, Constantino MJ, Fireman B, et al. Comorbid depression, chronic pain, and disability in primary care. Psychosomatic medicine. 2006;68(2):262-8.

20. Roca M, Gili M, Garcia-Garcia M, Salva J, Vives M, Campayo JG, et al. Prevalence and comorbidity of common mental disorders in primary care. Journal of affective disorders. 2009;119(1-3):52-8.

21. Gaynes BN, Rush AJ, Trivedi MH, Wisniewski SR, Balasubramani GK, Spencer DC, et al. Major depression symptoms in primary care and psychiatric care settings: a cross-sectional analysis. The Annals of Family Medicine. 2007;5(2):126-34.

22. Mainous AG, Baker R, Love MM, Gray DP, Gill JM. Continuity of care and trust in one's physician: evidence from primary care in the United States and the United Kingdom. Fam Med. 2001;33(1):22-7. 
23. VanBuskirk KA, Wetherell JL. Motivational interviewing with primary care populations: a systematic review and metaanalysis. Journal of behavioral medicine. 2014;37(4):768-80.

24. Unützer J, Park M. Strategies to improve the management of depression in primary care. Primary Care: Clinics in Office Practice. 2012;39(2):415-31.

25. Katon WJ, Lin EH, Von Korff M, Ciechanowski P, Ludman EJ, Young B, et al. Collaborative care for patients with depression and chronic illnesses. New England Journal of Medicine. 2010;363(27):2611-20.

26. Kessler R. Integrated Behavioral Health in Primary Care: Step-by-Step Guidance for Assessment and Intervention. Families, Systems \& Health: The Journal of Collaborative Family HealthCare. 2010 Dec;28(4):389-90.

27. Unützer J, Katon WJ, Fan M-Y, Schoenbaum MC, Lin EH, Della Penna RD, et al. Long-term cost effects of collaborative care for late-life depression. The American journal of managed care. 2008;14(2):95.

28. Siu AL, Bibbins-Domingo K, Grossman DC, Baumann LC, Davidson KW, Ebell M, et al. Screening for depression in adults: US Preventive Services Task Force recommendation statement. Jama. 2016;315(4):380-7.

29. Calonge N, Petitti DB, DeWitt TG, Dietrich AJ, Gordis L, Gregory KD, et al. Screening for depression in adults: US Preventive Services Task Force recommendation statement. Annals of internal medicine. 2009;151(11):784-92.

30. Jacques L, Jensen TS, Schafer J, Caplan S, Schott L. Decision Memo for Screening for Depression in Adults [Internet]. The Centers for Medicare \& Medicaid Services; 2011 Oct [cited 2021 Feb 17]. Report No.: CAG00425N. Available from: https://www.cms.gov/medicare-coverage-database/details/nca-decision-memo.aspx? NCAld=251

31. Löwe B, Kroenke K, Gräfe K. Detecting and monitoring depression with a two-item questionnaire (PHQ-2). Journal of psychosomatic research. 2005;58(2):163-71.

32. Colligan EM, Cross-Barnet C, Lloyd JT, McNeely J. Barriers and facilitators to depression screening in older adults: a qualitative study. Aging \& mental health. 2020;24(2):341-8.

33. Akincigil A, Matthews EB. National rates and patterns of depression screening in primary care: results from 2012 and 2013. Psychiatric services. 2017;68(7):660-6.

34. Samples H, Stuart EA, Saloner B, Barry CL, Mojtabai R. The Role of Screening in Depression Diagnosis and Treatment in a Representative Sample of US Primary Care Visits. Journal of General Internal Medicine. 2020 Jan 1;35(1):12-20.

35. Minkler M, Salvatore AL, Chang C. Participatory approaches for study design and analysis in dissemination and implementation research. In: Brownson RC, Colditz GA, Proctor EK, editors. Dissemination and implementation research in health: Translating science to practice. 2nd ed. Oxford, UK: Oxford University Press; 2018. p. 175-90.

36. Palinkas LA, Zatzick D. Rapid assessment procedure informed clinical ethnography (RAPICE) in pragmatic clinical trials of mental health services implementation: methods and applied case study. Administration and Policy in Mental Health and Mental Health Services Research. 2019;46(2):255-70.

37. Smith J, Rapport F, O'Brien TA, Smith S, Tyrrell VJ, Mould EV, et al. The rise of rapid implementation: a worked example of solving an existing problem with a new method by combining concept analysis with a systematic integrative review. BMC Health Services Research. 2020;20:1-14.

38. Austrian J, Mendoza F, Szerencsy A, Fenelon L, Horwitz LI, Jones S, et al. Applying A/B Testing to Clinical Decision Support: Rapid Randomized Controlled Trials. J Med Internet Res. 2021 Apr 9;23(4):e16651.

39. Wolk CB, Last BS, Livesey C, Oquendo MA, Press MJ, Mandell DS, et al. Addressing common challenges in the implementation of collaborative care for mental health: the Penn Integrated Care program. The Annals of Family Medicine. 2021;19(2):148-56.

40. Adaji A. Integrated care: A disruptive innovation for extending psychiatric expertise to primary care practices. Mayo Clinic Proceedings: Innovations, Quality \& Outcomes. 2018;2(2):99-102.

41. Unützer J, Katon W, Callahan CM, Williams Jr JW, Hunkeler E, Harpole L, et al. Collaborative care management of late-life depression in the primary care setting: a randomized controlled trial. Jama. 2002;288(22):2836-45.

42. Bower P, Gilbody S, Richards D, Fletcher J, Sutton A. Collaborative care for depression in primary care: making sense of a complex intervention: systematic review and meta-regression. The British Journal of Psychiatry. 2006;189(6):484-93.

Page $13 / 31$ 
43. Muntingh AD, van der Feltz-Cornelis CM, van Marwijk HW, Spinhoven P, van Balkom AJ. Collaborative care for anxiety disorders in primary care: a systematic review and meta-analysis. BMC family practice. 2016;17(1):1-15.

44. Terwiesch C, Ulrich KT. Innovation tournaments: Creating and selecting exceptional opportunities. Harvard Business Press; 2009.

45. Terwiesch C, Mehta SJ, Volpp KG. Innovating in health delivery: The Penn medicine innovation tournament. In: Healthcare. Elsevier; 2013. p. 37-41.

46. Stewart RE, Williams N, Byeon YV, Buttenheim A, Sridharan S, Zentgraf K, et al. The clinician crowdsourcing challenge: using participatory design to seed implementation strategies. Implementation Science. 2019;14(1):63.

47. Penn Medicine Center for Healthcare Innovation. Innovation Tournaments [Internet]. Philadelphia, PA; Available from: https://healthcareinnovation.upenn.edu/

48. Woike BA. Content coding of open-ended responses. In: Robins RW, Fraley CR, Kreuger RF, editors. Handbook of research methods in personality psychology. New York, NY: Guilford Press; 2007. p. 292-307.

49. Gehrig M. Instant-Runoff Voting [Internet]. St. Paul, MN: Minnesota House of Representatives; 2007 Feb. (Information Brief). Available from: https://www.house.leg.state.mn.us/hrd/pubs/irvoting.pdf

50. Thomke S. Enlightened experimentation: The new imperative for innovation. Harvard Business Review. 2001;79(2):66-75.

51. Asch DA, Rosin R. Innovation as discipline, not fad. New England Journal of Medicine. 2015;373(7):592-4.

52. Lemke DS, Fielder EK, Hsu DC, Doughty CB. Improved team performance during pediatric resuscitations after rapid cycle deliberate practice compared with traditional debriefing: a pilot study. Pediatric emergency care. 2019;35(7):480-6.

53. Horwitz LI, Kuznetsova M, Jones SA. Creating a learning health system through rapid-cycle, randomized testing. $N$ Engl $J$ Med. 2019;381(12):1175-9.

54. Sriram V, Jenkinson C, Peters M. Using rapid cycle tests of change to develop the Carers Assistive Technology Experience Questionnaire: a cognitive interview study in the UK. BMJ Open. 2021 Mar 1;11(3):e042361.

55. Hirshberg ABM, Vandertuyn M, Mahraj K. Rapid-cycle innovation testing of text-based monitoring for management of postpartum hypertension. JCOM. 2017;24(2).

56. Taylor MJ, McNicholas C, Nicolay C, Darzi A, Bell D, Reed JE. Systematic review of the application of the plan-do-studyact method to improve quality in healthcare. BMJ Qual Saf. 2014 Apr 1;23(4):290.

57. Rusch FR, Kazdin AE. Toward a methodology of withdrawal designs for the assessment of response maintenance. Journal of Applied Behavior Analysis. 1981;14(2):131-40.

58. Borkan J. Immersion/crystallization. In: Crabtree BF, Miller WL, editors. Doing qualitative research. 2nd ed. Thousand Oaks, CA: Sage Publications, Inc; 1999. p. 179-94.

59. Miller WL, Crabtree BF. Primary Care Research: A Multimethod Typology and Qualitative Roadmap. In: Miller WL, Crabtree BF, editors. Doing qualitative research. 1st ed. Newbury Park, CA: Sage Publications, Inc.; 1992. p. 3-28.

60. Miles MB, Huberman AM, editors. Qualitative data analysis: An expanded sourcebook. 2nd ed. Thousand Oaks, CA: Sage; 1994.

61. Martínez-González NA, Tandjung R, Djalali S, Rosemann T. The impact of physician-nurse task shifting in primary care on the course of disease: a systematic review. Human Resources for Health. 2015 Jul 7;13(1):55.

62. Dlamini-Simelane T, Moyer E. Task shifting or shifting care practices? The impact of task shifting on patients' experiences and health care arrangements in Swaziland. BMC Health Services Research. 2017 Jan 10;17(1):20.

63. Padmanathan P, De Silva MJ. The acceptability and feasibility of task-sharing for mental healthcare in low and middle income countries: a systematic review. Soc Sci Med. 2013 Nov;97:82-6.

64. Pilipenko N, Vivar-Ramon C. Depression Screening in a Primary Care Setting: Examining Perceptions and Experiences of English- and Spanish-Speaking Patients. J Clin Psychol Med Settings. 2020 Oct 28;

65. Kahalnik F, Sanchez K, Faria A, Grannemann B, Jha M, Tovian C, et al. Improving the identification and treatment of depression in low-income primary care clinics: a qualitative study of providers in the VitalSign6 program. International

Page $14 / 31$ 
Journal for Quality in Health Care. 2018;

66. Poghosyan L, Norful AA, Ghaffari A, George M, Chhabra S, Olfson M. Mental health delivery in primary care: The perspectives of primary care providers. Archives of psychiatric nursing. 2019;33(5):63-7.

67. Henry TL, Schmidt S, Lund MB, Haynes T, Ford D, Egwuogu H, et al. Improving Depression Screening in Underserved Populations in a Large Urban Academic Primary Care Center: A Provider-Centered Analysis and Approach. American Journal of Medical Quality. 2020;35(4):315-22.

68. Thombs BD, Ziegelstein RC. Does depression screening improve depression outcomes in primary care? Bmj. $2014 ; 348$.

69. Mojtabai R. Universal depression screening to improve depression outcomes in primary care: Sounds good, but where is the evidence? Am Psychiatric Assoc; 2017.

70. Pfoh ER, Janmey I, Anand A, Martinez KA, Katzan I, Rothberg MB. The impact of systematic depression screening in primary care on depression identification and treatment in a large health care system: A cohort study. Journal of General Internal Medicine. 2020;35:3141-7.

71. O'Connor EA, Whitlock EP, Beil TL, Gaynes BN. Screening for depression in adult patients in primary care settings: a systematic evidence review. Annals of internal medicine. 2009;151(11):793-803.

72. Darragh D. Response rate of Crowdsourcing Challenges through the Your Big Idea Platform. 2018.

73. Harder VS, Barry SE, French S, Consigli AB, Frankowski BL. Improving adolescent depression screening in pediatric primary care. Academic pediatrics. 2019;19(8):925-33.

74. Bose J, Zeno R, Warren B, Sinnott LT, Fitzgerald EA. Implementation of universal adolescent depression screening: quality improvement outcomes. Journal of Pediatric Health Care. 2021;

75. Bonawitz K, Wetmore M, Heisler M, Dalton VK, Damschroder LJ, Forman J, et al. Champions in context: which attributes matter for change efforts in healthcare? Implementation Science. 2020;15(1):1-10.

\section{Tables}

Table 1. Themes, Ideas, and Barriers from the Innovation Tournament 


\begin{tabular}{|ll}
\hline Idea & $\begin{array}{l}\text { Number Idea } \\
\text { of } \\
\text { Ideas }\end{array}$
\end{tabular}

Patient $4 \quad$ "Make sure there is information concerning Education depression. Offer incentives for patients. Give some example of why people are depressed"

"In addition to wraparound education on reducing stigma of depression and normalizing it as a mental health condition that can change over time, particularly with appropriate therapy/ resources, we could screen for depression using a "mood meter," or some sort of "tool", either a separate device or integrated onto screen, that gives brief explanation as to why we ask about mood state, then asks 'over the last 2 weeks, I've been feeling "content / stressed / down/ depressed" etc. Each mood state gets its own color. If one selects, "depressed/down/hopeless" - the screen/ "meter" could light up a specific color, i.e., green or purple, and stay that color until the PCP arrives in the room. The PCP will see the very evident signal, and can start a conversation acknowledging mental health - even if to say, "it looks like the last 2 weeks have been going well for you! Great to hear." Then move on with visit... obviously if light is "depression" signal, then PCP knows very clearly they need to follow up w/ [the PHQ]-9."

"I believe the office should set a group/days aside in the office for depression/anxiety. So many people in the world are going through these issues alone."

"I don't know if this idea will increase depression screening but I do think it has the potential to improve overall quality of care. I believe our current process, as it has been rolled out in my practice, is flawed. I believe it leads to inaccurate assessments and negatively impacts other aspects of the MAs rooming role including accurate BP [blood pressure] assessment. I believe this is a key aspect of what a provider should do with a patient, but we can think of prompts to avoid missing an opportunity when the agenda may overwhelm this issue. This could include simple signage that states something like - "Feeling blue? Talk to your provider." "Feeling blue/sad? Please complete this form and talk to your provider." The signs/form could be at the front desk, in the MA rooms or in the exam rooms. This is similar to a project I did several years go around smoking cessation that I think increased conversations but did not slow flow or lead to negative experiences for patients and our MAs."

Reframe $8 \quad$ "Change wording of questions \& separate
answers."
answers."

"Breaking down the questions in the PHQ-2. Change it to: "Have you been thinking about something that happened in your past recently that has been depressing?" This is because most people don't relate it to as depression, but

\section{Barriers}

"Not knowing how to get help, not wanting help"

"It gets overlooked because there is no standardized "checklist" or hard stop that ensures it gets done at every visit. There has been provider push back and gate keeping around when depression screening should be done, i.e. lack of recognition and prioritization despite evidence of benefit, and again no standardized expectation to perform and operationalize at the local level. We also need a greater focus on patient-centered efforts to explain why we are asking about depression on the delivery side as it may seem intrusive or confusing as to why we are seemingly "all of a sudden" more interested in if they're depressed or not. I can imagine that this may feel suspect without a context."

"Being afraid to speak up. That's why with a group you can physically see and hear from real people that are suffering from the same issues. Also physicians do not have the time to access a depression visit and a sick visit."

"The PHQ-9 is meant to be self administered. The MAs are ill-trained to do this effectively. Asking these questions while taking BP [blood pressure] negatively impacts both of these tasks. Depression needs to be considered at every visit and not based on some annual schedule. We are too wrapped up in process vs providing quality care."

"They way questions are being asked (feeling down, depressed or helpless). There's no separation (they might feel down, but not depressed or helpless or vice or versa)"

"The current wording of the PHQ-2 just doesn't make sense to the patients. Patients will often say no to this question. But, if you explore more and ask them to talk more. The question 
they are still thinking about things that make them sad."

"I think that some of the questions that are currently on our depression screening can be confusing for the patient in order for them to respond appropriately. Clearer questions that are less intrusive on the surface could be beneficial."

"How have you been feeling lately? Any feelings of being down or little interest?" is too long or the wording doesn't make sense."

"Patients don't always take these questions seriously and are just trying to get us out of the room in order to see their provider." over the last two weeks. Depression isn't always constant. Sometimes depression comes and goes, and two weeks is not a long enough time to determine that."
"Maybe we shouldn't limit the screening to just

"People get really offended. I think it's important for them to feel important and cared about. Some people take it that way or some people blow me off, like, [they say] "No," with a face that you can almost feel like there is something they are not telling us. I sometimes feel like I want to say, "Are you sure? We have resources," but I don't want to be pushy if they say no. I think there should be more follow-up questions, something to make them feel like they need to speak up because it's everyday they could be feeling like that and are almost hating life. I would hate for someone to not speak up and feel better."

“I'm not sure of any barriers but the procedure here at $[X X X]$, the medical assistant goes over the health screening for every patient during triage. It covers fall risk, abuse, weight loss, advanced directives and depression screening. If they screen positive for depression we mention in the chief complaint "depression" and in the comments, we write "PHQ9" so once the physician takes over they will know to continue the depression screening."

"The questions: Everyday, more than half the days and several days. Patient are sometimes confused about the days. The questions should be worded differently to accommodate the patients who are depressed but do not want to talk about it. After screening my patients, I ask about depression every visit because in my opinion I have a few that may slip through the cracks and the questions sometimes does not go across well, so I try to identify what's going on with the patient an then ask the questions again if they are confused and state they are depressed; I ask them, if anything is going on in their life within the last two weeks that they may want to talk about that might cause them to have some kind of depression"

"I think sometimes patients are reluctant to admit they may have depression, whether it is a cultural problem. Trying to make the patient feel comfortable during their visit so they admit there is an issue."

"Get to know your patient, I think that all physicians should know their patients, and be able to identify if something major has changed in their lives, just by looking at them or noticing a big change in their weight, blood pressure or any life-changing events. My experience is when I go to the doctor, the assistants are not that approachable and I do not feel $100 \%$ comfortable talking to them about anything personal such as, depression, suicide, or abuse. My idea is for the physician to take 5 minutes to ask these questions themselves, so they can get

\section{"As above [barrier listed in idea]"}

"They seem reluctant to talk to the Medical Assistants, rather speak to a nurse/or the doctor. There is not enough eye contact. The first question is too broad of a question? Do you have little interest or pleasure of doing things? Patients get a little taken. Patients think that some questions are weird, like 'Do you have trouble dressing?" 
a better understanding of what the patient is actually going through, I feel much better talking to my physician about suicidal thoughts, abuse from a loved one, or even depression, I don't want no one going around looking at me different, I know there is HIPAA, but really who actually follows HIPAA when it's someone you work with."

Self- $\quad 12 \quad$ "Each PSR holds a smart tablet and opens a report bookmarked PHQ-2 screen and the patient logs into MPM [MyPennMedicine] during check-in to complete the 2 questions. If negative - a pop-up to let the patient know the result is negative and some evidence-based mental wellness practices like mindfulness-based stress reduction and regular exercise. If positive - a pop-up to inform the patient, recommend the patient tell the provider, offer general resources. If positive - a notification goes to the provider via HCM tab (or other location readily available to the provider) and telephone encounter. The patient hands the tablet back to the PSR, who resets the form (logs the patient out). Next patient checks in rinse, wash, repeat. If the patient is not on MPM, then it's a good opportunity to encourage signing up and the tablet could have a second MPM signup bookmark, which would increase the use of MPM."

"Patients could complete screening for depression on iPads while they wait to be called back for their appointment. This way it would be done for most patients before they even get into the room. Moderate or severe scores could trigger automatic referral to PIC to take the PCP out of the equation."

"I think that we should just avoid a PHQ-2 altogether and hand the patient a PHQ-9 with check-in forms."

"Texting how you are feeling when you are feeling down or depressed to your primary care office or BH. Staff will respond back with a form screening questionnaire, based on answers, referrals are made to primary care provider, $\mathrm{BH}$ or crisis center is needed"

"As a PSA for 24 years, I see over 140 patients in our practice daily. Sitting on the front line, I encountered some patients with depressive disorder, difficulty expressing how they feel on a daily basis, I try to comfort and support patients as much as I can. I inform them we care and want to help. I sometimes find myself tearing up listening to the stories they tell but at the same time, trying to stay calm and professional and to provide the assistance they may need. My idea would be to help our patients the best we can, to go above and beyond the call of duty. Being that the patients may not be comfortable, afraid to open up, we can create a short form that can be attached to the pre- visit summary. We print a pre-visit summary for each patient on a daily basis. This form can provide questions that may help us to get the best care. Patients can then give this form to our Medical Assistance to review. if patients are in urgent
"The current state of our practice is to have MA's provide the screen during check-in. This adds to MA workflow and can distract from other check-in needs."

"Time. Visits are limited and there is way too much to cover as it is."
"Sometimes the patient would like to explain why they feel the way they feel about every PHQ question which may take up time. We are not properly trained to handle certain scenarios when it comes to comforting the patient."

"Patients not answering questions honestly. (questions are asked by medical assistants and some patient may be embarrassed to really disclose how they are feeling)"
"Patients may feel uncomfortable talking about their issue at the front desk, patients dealing with something so difficult may have a hard time trusting someone not knowing how this person may react to their situation, its very scary to share something so personal. We have an open office filled with a great deal of patients daily. So it is a little uncomfortable opening up. [XXX] is our practice CCBH worker, $[X X X]$ is our Social worker, they are very involved with our patients. Our patients feel comfortable with [XXX] and [XXX], these patients are escorted to a private area in the office to get the help needed. A short form attached to our pre-visit summary may be more comfortable and private for patients to document how they feel without someone knowing or hearing their current situation. This way, the patient can be pulled away from the front office to a secluded area in the office 
need of help, we can give the form to our $\mathrm{CCBH}$ worker."

"I think that if the patients are allowed to answer the PHQ-2 questions on their own they would be more receptive when it comes to those questions"

"Patient could answer these questions in the privacy of their homes, workplaces, or settings. These questions can be populated into the patients' chart prior to office visit, which makes the questions more accurate. The answers can be more accurate when answered by the patient. Patients are very hesitant to answer these questions when asked face to face. By offering this questionnaire in the online check-in process it will ensure completion."

"Give patient access to Mychart either by iPad or computer while to enter answers to depression screening questions. This would also be a good way to ask about domestic violence, have patients check their med list and list their complaints in review of systems format etc. Offer a small incentive to patients for completing the screening questions such as a Starbucks gift card or a pen"

"When I went to see a doctor at another institution 8 years ago, I was handed an iPad that was loaded by the check-in clerk with surveys and questionnaires that were selected based on the doctor I was seeing; my reason for visit; and my demographics including age and gender. By the time I saw the doctor, all that information was in the EHR and available for his use using a simple Smartphrase. The same occurs at CHOP when I visit a doctor with my child. Both sites use Epic. It is well established that patients are more likely to be forthcoming about personal issues with a tablet or kiosk than they are with a staff member (see, for example, https://www.annemergmed.com/article/S01960644(02)00080-X/abstract). My big idea is to make the provision of tablets a must-have element of EHR-based practice in every outpatient practice in the health system, and to have a PHQ-2 be part of the pre-visit survey completed on a tablet in the waiting room for patients due for screening."

"Send patient a MPM [MyPennMedicine] message 1-2 weeks before their appointment asking them to complete to save time at their appointment. This would allow them to complete in private without being rushed."

"Send a pre-visit (within 24-48 hours of the visit) message to patients via MPM

[MyPennMedicine] enabled and showing no PHQ-2 screening in the previous year, similar to the plan for social determinants of health. They could complete the Smart forms before the visit and if positive could be flagged in the chart." without anyone knowing. No patient should have to deal with this alone."

"From my experience, I feel that the patients do not always answer the PHQ-2 questions honestly and I think that this is because there is such a frown upon depression."

"Time is the biggest factor for screening patients for depression. By offering this feature, online check-in process cuts the time of triage by a great amount."

"Time and patient's reluctance to answer questions with the medical assistant"

"The single greatest barrier to effective screening is the workflow that has the questions asked verbally by rushed and inexpert medical assistants, and recorded on paper for transcription by busy clinicians. There is no workflow that uses paper that works well in our practice, and this is a prime example. The other barrier is a philosophy that tablets are somehow a luxury for affluent (procedure-based, RVU-dense) practices, and not a must-have element of an EHR. Tablets should be as much a part of the IT outlay for an outpatient practices as keyboards, printers, and up to date computers. When we ask practices to pay for elements of the EHR out of revenues, it conveys a message that a complete EHR is only something you can afford if you do procedures. This leads providers to eschew the labor-intensive paperbased parts of the visit including depression screening."

"I worry that the screening done by MAs is so impersonal and rushed that patients don't answer honestly, not unusual for patients coming in for depression to have 0/0 on PHQ2."

"So far, I think our practice has really improved our screening of patients with the MA's asking the PHQ-2 with vitals. However, there is a barrier that many patients are not being handed a PHQ-9 and, if they are, the PHQ-9s are being scanned in instead of manually entered in PennChart [Penn Medicine's version of Epic@)] to satisfy having completed the measure. Certainly, it is a barrier asking this question to patients who have a long-standing history of depression/mood disorder. Those patients should either receive a PHQ-9 or have a documented discussion of the diagnosis in 
the visit, but we lack a workflow to identify those patients unless they are known to provider they will be seeing. Another barrier is time. When we screen for depression and it is a new finding, it is important and takes up a lot of our $20 \mathrm{~min}$ of time with the patient. We would love having more behavioral health staff on site for assistance with this workflow."

"Confidential survey for any and all patients to take prior to or during the wait for his/her provider. Survey will ask the same, if not more, detailed questions about whether or not they have felt depressed in the last 1-3 months. I've noticed that a lot of patients feel as though the 2-week screening does not help give their provider good insight on how they have been feeling overall. I feel this will also give the patient a sense of control and privacy. Some patients do not want to answer the questions when we, the medical assistants, ask because we are not "trained" or "do not have the skills and knowledge" to do so. Furthermore, I feel that this would give the patients who are unsure if they are experiencing depression or any other mental issue, a good idea of what signs and symptoms to look for in their daily lives...I would like them to be able to identify the difference between normal life stressors and extreme stressors that are prolonged, causing life disruptions."

Workflow 7 "I think it would be helpful for the medical changes assistants to be properly trained in asking the depression screening questions and how to properly respond to the patients who are currently going through depression."
"Some patients do not want to answer the screening questions with anyone but the doctor because it is uncomfortable. Some patients state they do not need to answer the questions because they are receiving treatment elsewhere."

\begin{abstract}
"A lot of the times the clinical staff is the first person to go over the depression screening with the patient and when a patient is feeling depressed and tries to discuss it with the clinical staff, I feel that the staff does not always know how to properly react toward that patient to comfort them or explain the process with the physician going over the next steps to help the patient. My fear is the patient tried to converse with the MA prior but the MA's have such limited time with the patients when rooming and if the patient feels rushed or cut off by the time the physician comes in the patient may then feel closed off or shut the communication down since they couldn't openly communicate with the Medical Assistant. I feel if there is a proper training for the clinical staff on communication with the patients for the depression screening both the patient and the medical assistant would feel more comfortable is asking the questions with a better understanding on how to react."
\end{abstract}

\section{"No significant barriers currently."}

\begin{abstract}
"At the $[X X X]$ clinic, RN/MA's are scoring PQH-2 during the check-in process. This is a perfect time to do screening as patients often are just waiting for their physicians to arrive. However, as a resident doctor I didn't realize this was being done or where to look for the score until I asked another colleague in the clinic. It would be helpful to 1) do this screening in other clinics if not already adapted and 2) spread awareness that $i$ ) this screening is now in place at our practice and ii) where to look for the PHQ-2 score in the electronic system. This can be done by sending a bulletin email to the providers in the practice."
\end{abstract}

"A provider believing that they will be forced to

"I think the best way to increase screening is to

Page 20/31 
actually remind the primary care provider to ask these two questions during the exam via a Best Practice Advisory flag once the chart is open and the patient is in the room. It should be a reminder only to complete the PHQ-2. If they want to, they can by-pass it but it may improve the number of patients screened if the primary care provider is aware that they do not need to directly address the results at the time of the appointment unless the appointment is for mental health purposes in which case the questionnaire is a moot point."

"I have created a visit tool for the Medical Assistants to use in our office. The Medical Assistants use this form to remind them to review all of the meaningful use/quality questions. If the patient has a positive PHQ-2 the Medical Assistant documents this on the Chief Complaint along with the reason for the visit. Example. Patient here for follow up of hypertension (positive PHQ-2) the physician then knows to complete the PHQ 9."

"The idea would consist of asking all patients who are coming in for an annual exam or coming in with a set of chief complaints (insomnia, fatigue, sleep apnea, narcotic refill, back pain) the following question. "In the last 2 week have you noticed any change in your mood, be it worsening depression and anxiety". If answered yes, this would prompt a PHQ2 or 9. One feature of this initiative would be the need for EPIC to capture this information as an adequate screen. This could simply be done by clicking a "yes/no" button that says. "I have screened this patient for depression."

"The PHQ-2 screening is a good starting point. This can be done by medical assistants just as vital signs are done. The problem is finding the information in the chart and knowing if it's even there to find. It's unclear at each practice if PHQ2 's are already being done all the time, some of the time, or never. Most primary care doctors include vital signs in their note. Personally, I review the vital signs that are unloaded into my note as I am writing the note and during the visit. If the PHQ-2 was added to the vital sign portion so it would be uploaded with typical vital signs or if more physicians included PHQ-2 results to upload into the note, I think this would increase depression screening. If the MA's would give patients who screened positive on PHQ-2, the full PHQ-9 and GAD-7 questionnaires, this would save significant time and be very helpful for the visit."

"Many barriers exist to screen adults for depression including the fact that many adults at risk for depression do not schedule or keep appointments for themselves. However, these adults may encounter primary care practices many times throughout the year when they present with family members including aging parents or young children. Pilot data across many primary care sites has demonstrated that screening mothers who attend well child visits is an effective platform to screen for depression and provide care for women at risk for depression. It is possible to build on this idea and extrapolate to other adults who present to address the results at the current visit will create the perception that this screening tool is going to prolong the appointment and create further schedule delays."
"The practice was understaffed for an extended amount of time."

\begin{abstract}
"There is often not sufficient time to do a full depression screen during a visit. Also, if depression is discovered, there is often not enough time to do a full psychosocial evaluation and discuss treatment. This often takes a full 30 minute visit on it's own and there are often other chronic health issues to

discuss."
\end{abstract} "Time, remembering to do it on all patients,
not knowing if it was already done by the MA
and where that information is"
"1. Limited time to address multitude of patient concerns

2. Workflow which does not effectively operationalize screening by non-providers 3. Absence of case management services within the practice" 
primary care appointments with their spouses, partners or relatives. While not all family members will necessarily have their primary care within UPHS, a significant proportion will. Screening family members during routine primary care visits using a validated tool could close the gap in depression screening and improve care for patients and their families."

1

No idea

"Barriers: Not enough time during visits. Way too much to address at each visit; screening often takes a back seat to active issues. No quick way to identify last time someone was screened."

Note. The innovation tournament submissions have been lightly edited for readability and blinded to protect participant confidentiality. One person did not submit an idea but did submit a barrier, which is listed in the bottom row of the table.

Table 2. Themes and Ideas from the Panel Discussion 


\begin{tabular}{|c|c|c|c|}
\hline $\begin{array}{l}\text { Barrier } \\
\text { Themes }\end{array}$ & Sub-Themes & Frequency & Representative Quotes \\
\hline \multirow[t]{3}{*}{$\begin{array}{l}\text { Medical } \\
\text { assistant } \\
\text { administration } \\
\text { of the PHQ-2 }\end{array}$} & \multirow[t]{2}{*}{$\begin{array}{l}\text { Medical } \\
\text { assistant } \\
\text { training is key }\end{array}$} & \multirow[t]{2}{*}{4} & $\begin{array}{l}\text { "Medical Assistants may not be appropriate to administer the PHQ, } \\
\text { because they have very limited training. In other places, nurses do the } \\
\text { screening and they're much better trained, and the results are more } \\
\text { accurate. It's a much more costly option, but overall (not just for } \\
\text { depression) it's led to much better outcomes. Penn has decided to use } \\
\text { medical assistants for vitals and you get what you pay for." }\end{array}$ \\
\hline & & & $\begin{array}{l}\text { "Medical Assistants often have a great relationship with patients, and an } \\
\text { interpersonal connection. I see the Medical Assistants in my practice } \\
\text { stopping by patients' doors and saying hello. They really have a deep } \\
\text { connection. They could, with the right training, be important in getting the } \\
\text { screenings done with the patients feeling comfortable." }\end{array}$ \\
\hline & $\begin{array}{l}\text { The PHQ is } \\
\text { not validated } \\
\text { for clinician } \\
\text { administration }\end{array}$ & 4 & $\begin{array}{l}\text { "Self-directed PHQ-2s are: (a) validated (it was how the tool was } \\
\text { designed to be administered) and (b) gives the patient different options } \\
\text { for how to fill it out (iPad, MyPennMedicine, etc.)" }\end{array}$ \\
\hline \multirow[t]{2}{*}{$\begin{array}{l}\text { Understanding } \\
\text { the rationale } \\
\text { for screening }\end{array}$} & $\begin{array}{l}\text { Clinicians } \\
\text { don't } \\
\text { understand }\end{array}$ & 2 & $\begin{array}{l}\text { "The biggest problem is that many people don't know what the concept } \\
\text { of "screening" is. It's hard enough training residents on this, let alone } \\
\text { medical assistants. For screening, you're wanting to find the person who } \\
\text { has slid under the radar, not the patient you already know has depression } \\
\text { and is sad. That patient doesn't need to be screened." }\end{array}$ \\
\hline & $\begin{array}{l}\text { Patients don't } \\
\text { understand }\end{array}$ & 2 & $\begin{array}{l}\text { "The patients are missing an explanation for why the practices are doing } \\
\text { the screening in the first place and giving patients resources for what's } \\
\text { going to happen if they screen positive." }\end{array}$ \\
\hline \multirow[t]{2}{*}{$\begin{array}{l}\text { Technological } \\
\text { challenges }\end{array}$} & \multirow[t]{2}{*}{$\begin{array}{l}\text { Health system } \\
\text { technological } \\
\text { challenges }\end{array}$} & \multirow[t]{2}{*}{2} & $\begin{array}{l}\text { "An idea that's missing is that it is really hard to find the PHQ in } \\
\text { PennChart [Penn Medicine's version of Epic@ C] due to the way it's } \\
\text { configured. Doctors get very frustrated. Place it in a standard, permanent } \\
\text { place in PennChart." }\end{array}$ \\
\hline & & & $\begin{array}{l}\text { "In Psychiatry, no one knows where to find the PHQ-9 because they don't } \\
\text { have "vitals" on their dashboard. So, this presents problems." }\end{array}$ \\
\hline Ideas & Themes & Frequency & Representative Quotes \\
\hline \multirow[t]{2}{*}{ Reframing } & \multirow[t]{2}{*}{$\begin{array}{l}\text { Reframing is } \\
\text { invalid }\end{array}$} & \multirow[t]{2}{*}{4} & $\begin{array}{l}\text { "Re-framing is the most surprising idea to me. I thought that we would } \\
\text { see mostly self-report responses. The PHQ-2 is validated to be a self- } \\
\text { report measure so it should be a self-report... Don't change the items on } \\
\text { the PHQ because it's a validated measure." }\end{array}$ \\
\hline & & & $\begin{array}{l}\text { "To me, the re-framing idea reflects the challenging piece that staff } \\
\text { (medical assistants, residents, attendings) aren't properly aware or } \\
\text { trained about the PHQ-2 and aren't fully knowledgeable about what } \\
\text { screening is." }\end{array}$ \\
\hline \multirow{2}{*}{$\begin{array}{l}\text { Patient self- } \\
\text { report }\end{array}$} & \multirow{2}{*}{$\begin{array}{l}\text { Tablet } \\
\text { computers in } \\
\text { the waiting } \\
\text { area }\end{array}$} & \multirow[t]{2}{*}{5} & "Do the PHQ-9 on tablets during waiting room downtime." \\
\hline & & & $\begin{array}{l}\text { "If looking at patient screening as a long-term project, the percentage of } \\
\text { people who are comfortable with technology will increase over time. So, } \\
\text { it's not a bad investment in the long-term." }\end{array}$ \\
\hline \multirow[t]{2}{*}{$\begin{array}{l}\text { Patient } \\
\text { education }\end{array}$} & \multirow[t]{2}{*}{$\begin{array}{l}\text { Education is } \\
\text { necessary }\end{array}$} & \multirow[t]{2}{*}{5} & $\begin{array}{l}\text { "Patient education is easy, quick, feasible to pilot. You can put signs in } \\
\text { waiting rooms." }\end{array}$ \\
\hline & & & $\begin{array}{l}\text { "One way to combine patient education and making this a workflow } \\
\text { change, is potentially thinking about depression screening as the "fifth } \\
\text { vital sign" like they did with pain." }\end{array}$ \\
\hline
\end{tabular}

Table 3. Rapid Prototyping Process for Tablets 


\begin{tabular}{|c|c|c|c|c|c|c|}
\hline & & Day 1 & Day 2 & Day 3 & Day 4 & Day 5 \\
\hline \multirow[t]{5}{*}{$\begin{array}{l}\text { Design } \\
\text { Summary }\end{array}$} & $\begin{array}{l}\text { Screening } \\
\text { Location }\end{array}$ & Waiting Room & Exam Room & Waiting Room & Waiting Room & Waiting Room \\
\hline & $\begin{array}{l}\text { Assigning the } \\
\text { Questionnaire }\end{array}$ & $\begin{array}{l}\text { The Patient } \\
\text { Service } \\
\text { Associate } \\
\text { (PSA) assigned } \\
\text { the patient the } \\
\text { questionnaire } \\
\text { at check-in and } \\
\text { provided the } \\
\text { research team } \\
\text { with the patient } \\
\text { codes after } \\
\text { check-in. The } \\
\text { PSA would } \\
\text { signal to } \\
\text { research team } \\
\text { when a patient } \\
\text { needed to be } \\
\text { screened. }\end{array}$ & $\begin{array}{l}\text { The PSA } \\
\text { assigned the } \\
\text { questionnaire } \\
\text { to patients at } \\
\text { check-in. PSA } \\
\text { would signal } \\
\text { when a patient } \\
\text { needed to be } \\
\text { screened. } \\
\text { Research } \\
\text { team received } \\
\text { the patient } \\
\text { codes ahead } \\
\text { of the shift } \\
\text { and input the } \\
\text { codes in the } \\
\text { tablet. }\end{array}$ & $\begin{array}{l}\text { The PSA } \\
\text { assigned the } \\
\text { questionnaire } \\
\text { at check-in. } \\
\text { PSA would } \\
\text { signal when a } \\
\text { patient needed } \\
\text { to be screened. } \\
\text { Research team } \\
\text { received the } \\
\text { patient codes } \\
\text { ahead of the } \\
\text { shift and input } \\
\text { the codes in } \\
\text { the tablet. }\end{array}$ & $\begin{array}{l}\text { The PSA } \\
\text { assigned the } \\
\text { questionnaire } \\
\text { to patients the } \\
\text { morning } \\
\text { before the } \\
\text { shift (well } \\
\text { before check- } \\
\text { in). The PSAs } \\
\text { entered the } \\
\text { patient code in } \\
\text { the tablets } \\
\text { before } \\
\text { handing the } \\
\text { tablets to } \\
\text { patients. }\end{array}$ & $\begin{array}{l}\text { The PSA } \\
\text { assigned the } \\
\text { questionnaire } \\
\text { at check-in. } \\
\text { The PSAs } \\
\text { entered the } \\
\text { patient code in } \\
\text { the tablets } \\
\text { before handing } \\
\text { the tablets to } \\
\text { patients. }\end{array}$ \\
\hline & $\begin{array}{l}\text { Tablet Hand- } \\
\text { off }\end{array}$ & $\begin{array}{l}\text { Research team } \\
\text { held onto } \\
\text { tablets and } \\
\text { approached } \\
\text { patients with } \\
\text { the tablet and } \\
\text { took the tablet } \\
\text { back from the } \\
\text { patient. }\end{array}$ & $\begin{array}{l}\text { Research } \\
\text { team held } \\
\text { onto the } \\
\text { tablets. When } \\
\text { the patient } \\
\text { was called to } \\
\text { the exam } \\
\text { room we } \\
\text { accompanied } \\
\text { the patient } \\
\text { and MA. }\end{array}$ & $\begin{array}{l}\text { Research team } \\
\text { held onto } \\
\text { tablets and } \\
\text { approached } \\
\text { patients with } \\
\text { the tablet and } \\
\text { took the tablet } \\
\text { back from the } \\
\text { patient. }\end{array}$ & $\begin{array}{l}\text { The PSAs } \\
\text { gave patients } \\
\text { the tablet at } \\
\text { check-in. } \\
\text { Patients were } \\
\text { instructed to } \\
\text { fill out the } \\
\text { PHQ while in } \\
\text { the waiting } \\
\text { room and to } \\
\text { bring back the } \\
\text { tablet to the } \\
\text { front desk as } \\
\text { soon as they } \\
\text { were finished. }\end{array}$ & $\begin{array}{l}\text { The PSAs gave } \\
\text { patients the } \\
\text { tablet at check- } \\
\text { in. Patients } \\
\text { were instructed } \\
\text { to fill out the } \\
\text { PHQ while in } \\
\text { the waiting } \\
\text { room and to } \\
\text { bring back the } \\
\text { tablet to the } \\
\text { front desk as } \\
\text { soon as they } \\
\text { were finished. }\end{array}$ \\
\hline & Administration & $\begin{array}{l}\text { Research team } \\
\text { assisted } \\
\text { patients if they } \\
\text { had questions. } \\
7 \text { out of } 8 \\
\text { patients } \\
\text { completed the } \\
\text { PHQ-2 on the } \\
\text { tablet and } 1 \\
\text { patient was } \\
\text { roomed early } \\
\text { and completed } \\
\text { the PHQ } \\
\text { verbally in the } \\
\text { exam room } \\
\text { with the } \\
\text { medical } \\
\text { assistant (MA). }\end{array}$ & $\begin{array}{l}\text { Research } \\
\text { team assisted } \\
\text { patients if } \\
\text { they had } \\
\text { questions. } 5 \\
\text { out of } 7 \\
\text { patients } \\
\text { completed the } \\
\text { PHQ-2 on the } \\
\text { tablet. } 1 \text { did it } \\
\text { verbally } \\
\text { because the } \\
\text { PSA forgot to } \\
\text { assign the } \\
\text { questionnaire. } \\
1 \text { did it } \\
\text { verbally } \\
\text { because the } \\
\text { patient was } \\
\text { blind. }\end{array}$ & $\begin{array}{l}\text { Research team } \\
\text { assisted } \\
\text { patients if they } \\
\text { had questions. } \\
5 \text { out of } 8 \\
\text { patients } \\
\text { completed the } \\
\text { PHQ-2 on the } \\
\text { tablet. } 1 \text { was } \\
\text { very frail and } \\
\text { elderly and } \\
\text { could not } \\
\text { operate the } \\
\text { tablet. } 2 \\
\text { patients were } \\
\text { called into the } \\
\text { exam room } \\
\text { before the } \\
\text { research team } \\
\text { was able to } \\
\text { administer the } \\
\text { questionnaire. }\end{array}$ & $\begin{array}{l}\text { Patient self- } \\
\text { administered } \\
\text { the PHQ-2. } 6 \\
\text { out of } 7 \\
\text { patients } \\
\text { completed the } \\
\text { PHQ-2 on the } \\
\text { tablet. } 1 \text { had } \\
\text { completed the } \\
\text { questionnaire } \\
\text { prior to their } \\
\text { visit because } \\
\text { they received } \\
\text { an email to fill } \\
\text { out the } \\
\text { questionnaire } \\
\text { before their } \\
\text { appointment. }\end{array}$ & $\begin{array}{l}\text { Patient self- } \\
\text { administered } \\
\text { the PHQ-2. } 6 \\
\text { out of } 6 \text { eligible } \\
\text { patients } \\
\text { completed the } \\
\text { PHQ-2 on the } \\
\text { tablet. }\end{array}$ \\
\hline & Follow-Up & $\begin{array}{l}\text { The plan was } \\
\text { that if the } \\
\text { patient }\end{array}$ & $\begin{array}{l}\text { The plan was } \\
\text { that if the } \\
\text { patient }\end{array}$ & $\begin{array}{l}\text { The plan was } \\
\text { that if the } \\
\text { patient }\end{array}$ & $\begin{array}{l}\text { The plan was } \\
\text { that if the } \\
\text { patient }\end{array}$ & $\begin{array}{l}\text { The plan was } \\
\text { that if the } \\
\text { patient }\end{array}$ \\
\hline
\end{tabular}




$\begin{array}{|lll|}\text { Workflow } & \begin{array}{l}\text { screened } \\ \text { positive, the MA } \\ \text { put down a red } \\ \text { sheet of paper } \\ \text { to notify } \\ \text { physician. }\end{array} \\ & \begin{array}{l}\text { Patient } \\ \text { Perspective }\end{array} & \begin{array}{l}\text { 4 out of } 7 \\ \text { patients } \\ \text { indicated that } \\ \text { they liked } \\ \text { answering } \\ \text { questions on } \\ \text { tablets and that } \\ \text { they were easy } \\ \text { to use. }\end{array} \\ & & \end{array}$

screened

positive, the

MA put down

a red sheet of

paper to notify

physician.

4 out of 5

patients

indicated that

the tablet was

acceptable

and more

confidential. screened

MA put down a

red sheet of

paper to notify

physician.

5 out of 5

patients who

indicated that

they were easy

to use and that

they preferred

self-report over

the MA asking

them

questions. positive, the

used the tablet

screened

positive, the

MA put down

a red sheet of

paper to notify

physician.

6 out of the 6

patients who

used the tablet

indicated that

tablets were

easy to use

and fast. All of

the patients

brought the

tablet back to

the front desk

when they

were finished.

Patients

reported no

barriers to

completing

the

questionnaires

on the tablets.

\section{Staff \\ Perspective}

\section{PSAs said the}

process was

fairly

straightforward.

They were

initially

confused about

assigning the

depression

screening

questionnaire

(several

processes and

codes they

needed to

enter) but by

the final patient,

the time it took

to assign the

questionnaire

decreased from

as much as 5

minutes to less

than 1 minute.
The MA said

that the

process of

completing

the PHQ-2 in

the exam

room worked

better than the

waiting room

because in the

waiting room,

patients don't

have privacy.
PSAs indicated

that the

process

(assigning the

questionnaire)

was

increasingly

straightforward

as long as they

did not have to

handle the

tablets. They

said the

instructions

were helpful

and clear.
PSAs who had

all

participated in

the pilot in

previous shifts

were now

familiar with

the workflow,

with how to

use the

tablets, and

how to

introduce the

study. PSAs

also

remembered

to assign the

questionnaire

to all

The PSAs also

handed the

tablet to

patients, so it

was obvious

which patients

were the

physician's

and who

needed to be

interviewed. participants.

The MA

indicated that

the tablet

process has

been

straightforward

and cuts down

on what they

have to do,

which is a

benefit. They

hoped that

many other

questions

could be put on

the tablet.

PSAs

described the

final day of

piloting as

"smooth

sailing" as they

got

accustomed to

the process.

They were

surprised by

how many

patients

remembered to

return the

tablets.
Physician did

not report

noticeable

changes.

Physician

indicated that

from their

perspective, the

tablet process

has been

smooth.

been "working

great."
1 patient

1 patient who 3 patients

had could not

completed the

answer the

1 patient
reported
wanting an

voiced extreme dislike of the 
tablets and/or questions and required assistance. 1 patient took a long time (20 minutes) to complete the $\mathrm{PHQ}$.
PHQ-2 on the tablet had not authorized

their

responses and therefore, the

responses

were not

submitted. 1

patient was

blind,

suggesting a

need for a

back-up plan.

1 patient

voiced

strongly

disliking the

tablet.

Patients took a long time to complete the tablet from 212 minutes. 1 patient asked that we use disinfectant wipes. depression screener on the tablet. option to fill

out the

questionnaire

online ahead

of their appointment.

Another

patient

expressed

worries about

getting sick

from touching the tablets. tablets and said that they preferred to talk to a person.
PSAs

expressed

feeling

overwhelmed

frustrated with

the additional

burden, and

needing more

explicit

instructions

and reminders

to assign the

patients the

questionnaire. prototyping

shift to assign

before check-in.
PSAs

expressed

needing

reminders to

assign the

questionnaires,

because they

sometimes

forgot. number) at the beginning of 


$\begin{aligned} & \text { questionnaire } \\ & \text { confidential } \\ & \text { through the }\end{aligned}$
confidential portal).
patient portal.
One patient
saw that the
questionnaire
had been
assigned to
them via email
and
completed the
PHQ-2 prior to
check-in.

\section{Despite \\ having \\ disinfecting \\ wipes, the \\ PSAs \\ reiterated \\ concerns \\ about illness \\ (many sick \\ patients were \\ in the office).}

$\begin{array}{ll}\text { Clinician } & \text { Physician had } \\ \text { Perspective } & \text { no constructive } \\ & \text { feedback this } \\ & \text { cycle. }\end{array}$

The physician
reported that
the MA was
placing the red
paper down
when the
patient
completed the
PHQ-9 *not*
when the
patient scored
positive on it.
Physician said
additional MA
training was
needed.

Physician indicated that despite additional training, the MA continued to place a red paper down even when the patient had not screened positive on the PHQ-9.
Physician indicated that no constructive feedback this cycle. going forward suicide protocols were needed. In addition, physician felt it was important that the electronic health record had only place to enter PHQ data.

\section{Technical and Workflow Challenges}

One of the tablets did not work.
The other tablet was still being fixed, leaving the team with only one tablet.
Research team did not have a patient list with names, making it difficult to tell which patients should be screened.

\section{PSAs forgot to} assign the questionnaires and had to be reminded.

Research team
was stationed
on the other
side of the
waiting room
from the
entrance and
front desk. That
made it difficult
to identify
patients for the
questionnaire.

questionnaire.

\section{PSAs} sometimes questionnaire and 1 PSA had not been trained in how to assign the questionnaire and, so, required additional training during a busy moment.
Research team did not have the
In the exam room, the MA 
physician's

schedule ahead

of time, so did

not know which

patients to look

for or the code

to enter in the

tablet computer had to wait a

long time for

patients to

complete the

questionnaire, delaying the

pre-visit vitals

assessment.

The MA still

had to ask

other

questions to

the patient

and indicated

that those

questions

should also be

included in the

tablet

questionnaire.
The tablet only held a charge

for $\sim 3$ hours

and needed to

be plugged in.

Mid-rapid

cycle

prototyping

shift, a new

MA who had

not been

trained in the

protocol saw

the physician's

patients.

Refrne the PSA

Create a 3-

sentence script

for PSAs to say

when handing

tablets to the

patients.
Refine the PSA

script and

provide more

specific

instructions

(with

screenshots)

for PSAs

\begin{tabular}{|c|c|}
\hline $\begin{array}{l}\text { Attempt to } \\
\text { have PSAs } \\
\text { hand off the } \\
\text { tablet and ask } \\
\text { patients to } \\
\text { return the } \\
\text { tablet to the } \\
\text { PSA. Ask PSAs } \\
\text { to assign all } \\
\text { eligible } \\
\text { patients the } \\
\text { PHQ } \\
\text { questionnaire } \\
\text { before the shift } \\
\text { to reduce time } \\
\text { at check-in. }\end{array}$ & $\begin{array}{l}\text { Provide } \\
\text { additional } \\
\text { disinfecting } \\
\text { wipes to PSAs } \\
\text { per their } \\
\text { request } \\
\text { (beyond the } \\
\text { ones already } \\
\text { given to } \\
\text { patients). }\end{array}$ \\
\hline
\end{tabular}

Retrain MAs

about protocol.

Ensure that the

MA is only

putting the red

paper down

when the

patient screens

positive, not

just when they

complete the

PHQ-9. the patient

screens

positive, not

just when they

complete the

PHQ-9.

\section{Technical Changes}

$\begin{array}{ll}\text { Station } & \text { One patient } \\ \text { ourselves next } & \text { suggested } \\ \text { to the front } & \text { disinfectant } \\ \text { desk and near } & \text { wipes to wipe } \\ \text { an electrical } & \text { down the } \\ \text { outlet for ease } & \text { tablet because }\end{array}$

Revert to assigning the questionnaires at check-in to avoid patients completing 
of charge and for easier access to see patients and to hand the tablet to the PSAs. many patients

are sick.

Research

team will bring

disinfecting

wipes next

time for the

tablets.

Request the

identifying

number from

the practice

manager ahead

of the shift so

we can enter it

in the tablet as

soon as the

patient checks

in.
Research

team will ask

about the MA

schedule to

ensure that

the MAs

working

during the

next rapid

prototyping

cycle are

trained. the PHQ-2 at

home through

the

confidential

patient portal.

\section{Administer the patient questionnaire in the exam room. \\ Despite the \\ privacy \\ advantages of \\ the exam \\ room for the \\ sake of time, \\ administer the \\ patient \\ questionnaire \\ in the waiting \\ area.}

Remind

patients to

authorize their

responses

when

completing

the PHQ-2 on

the tablet.

\section{Figures}






Researchers from Psychiatry and Primary Care are launching a Your Big Idea Challenge to crowdsource ideas from frontline clinicians and staff like you!

We want to know, what's your big idea for increasing depression screening rates in the primary care setting?

Submit an idea in less than five minutes and have a chance to win $\$ 100$ !

\section{https://bigidea.pennmedicine.org/depression}

Figure 1

Flyer Advertising the Innovation Tournament in PIC practices 


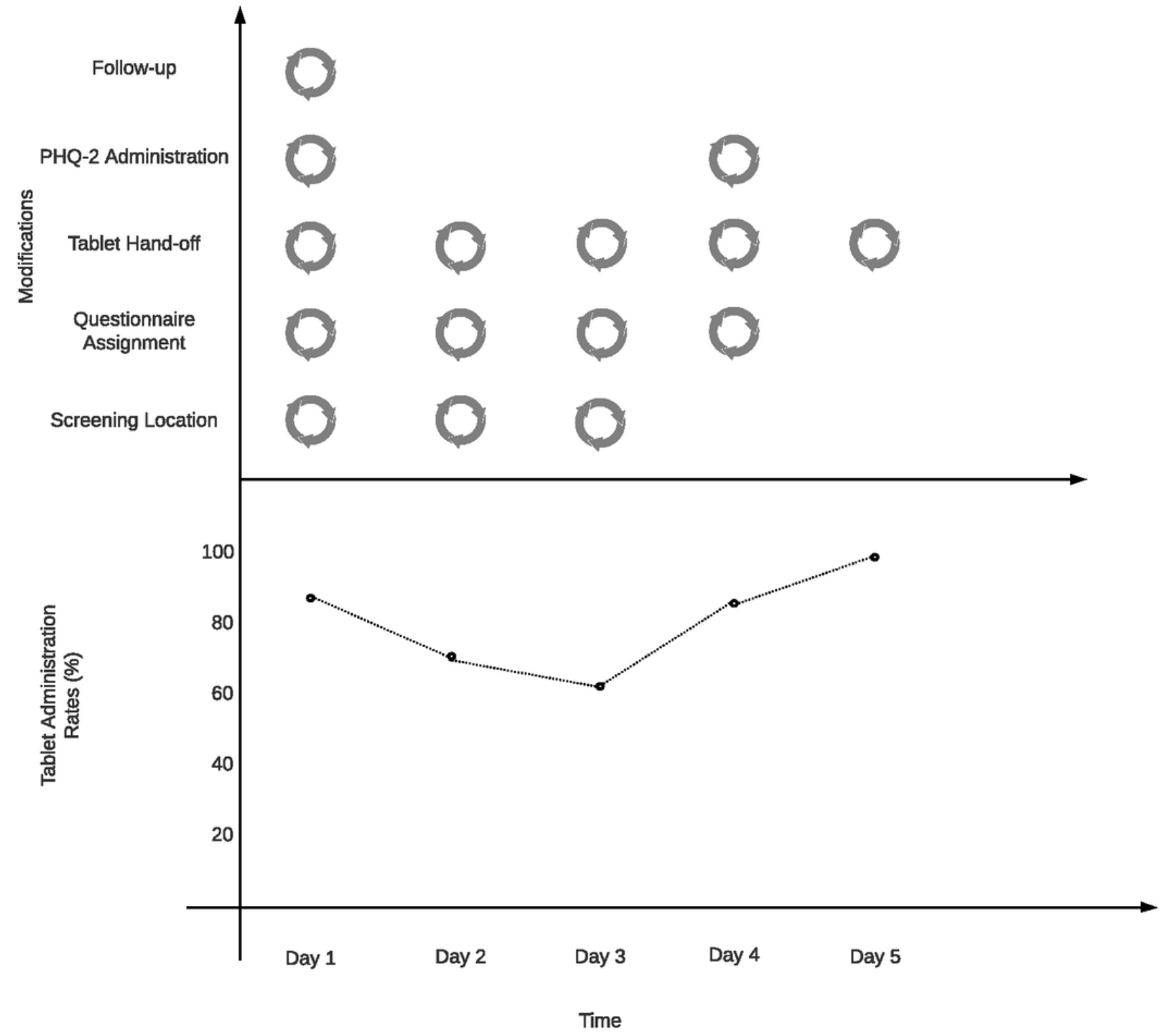

\section{Figure 2}

Rapid Prototyping Changes and Tablet Administration Note. Rapid prototyping cycle icons are present in the upper window of the figure if modifications were made to this aspect of the piloting strategy based on decisions from the previous cycle. It should be noted that during piloting, though not all patients were administered the questionnaire via tablet, all patients completed the PHQ-2 (with the exception of one patient during the first cycle).

\section{Supplementary Files}

This is a list of supplementary files associated with this preprint. Click to download.

- AdditionalFile1.docx

- AdditionalFile2.docx

- AdditionalFile3.docx 